\title{
The Effectiveness of Developmentally Supportive Positioning on Preterm Infants' Pain Response at Neonatal Intensive Care Units
}

\author{
Fawzia El Sayed Abusaad", *, Rehab Abd El Aziz El Sayed Abd El Aziz ${ }^{1}$, \\ Nehad Abd Elsallam Nasef ${ }^{2}$ \\ ${ }^{1}$ Pediatric Nursing Department, Faculty of Nursing, Mansoura University, Mansoura City, Egypt \\ ${ }^{2}$ Pediatric Medicine Department, Faculty of Medicine Mansoura University, Mansoura City, Egypt
}

Email address:

fawziaabusaad2013@gmail.com (F. El S. Abusaad)

*Corresponding author

\section{To cite this article:}

Fawzia El Sayed Abusaad, Rehab Abd El Aziz El Sayed Abd El Aziz, Nehad Abd Elsallam Nasef. The Effectiveness of Developmentally Supportive Positioning on Preterm Infants' Pain Response at Neonatal Intensive Care Units. American Journal of Nursing Science. Vol. 6, No. 1, 2017, pp. 63-71.doi: 10.11648/j.ajns.20170601.18

Received: December 22, 2016; Accepted: January 5, 2017; Published: January 28, 2017

\begin{abstract}
Preterm infants are exposed to serious health problems that require advanced highly specialized nursing skills in order to sustain their life. Developmental positioning is one of an essential skill for neonatal intensive care unit nurses. This study aimed to investigate the effectiveness of developmentally supportive positioning on preterm infants' pain responses at NICU. A Quasi experimental design was used to conduct the study at neonatal intensive care unit on a sample of (56)preterm infants who admitted through nine months and were equally divided randomly into the study and control group after fulfilling the inclusion criteria using demographic characteristics of Preterm infants. Infant Position Assessment Tool (IPAT) and Preterm Infant Pain Profile (PIPP) Tool. The results indicated that all the preterm infants $(100 \%)$ had an unacceptable positioning in both groups, and none of preterm infants in both groups had no- or- minimal pain at baseline assessment. While after one week of intervention about two third (64.3\%) of the infants were placed in an acceptable position in the study group and only less than one quarter (21.4\%) of the preterm infants in the control group were placed in an acceptable position. Regarding pain response at day seven of intervention five minutes after morning routine care, about half (53.6\%) of infants in the study group had no-or-minimal pain while none of infants in the control group had no-or-minimal pain and about one third (32.1\%) of infants in the control group had severe pain and none of the infants in the study group had severe pain. The present study concluded that preterm infants who were placed in developmentally supportive positioning had acceptable position and exhibited less pain scores. It is recommended to replicate the present study on a larger sample.
\end{abstract}

Keywords: Infant Position Assessment, Preterm Infant Pain Profile, Developmental Supportive Positioning

\section{Introduction}

Preterm infants delivered before37 weeks of gestational age were exposed to interruption in their intrauterine growth which exposed them to a totally different environment beside their immature organs that required special care not like the normal newborn care environment of swaddling, feeding and holding. Preterm infants are a particularly vulnerable population due to multiple factors such as genetic endowment, physical, social environment, chronic stress and health care which required technologically advanced medical interventions and highly specialized nursing care in order to survive and thrive $[1,2]$. The incidence of preterm births over the last 25 years has been relatively constant at approximately $12 \%$ of living births in the United States, about 500,000 infants every year, while in Egypt it is about $7.3 \%[3]$.

The preterm infants often exhibit lack of adequate muscle tone; those infants are at greater risk for developing abnormal movement pattern as well as skeleton deformation and longterm neurodevelopmental disability. Some delays are related 
to postural problems and improper body mechanics rather than their neurological impairment. Hypotonic or decreased muscle tone was observed in the infant born 28 to 30 weeks of gestation. Proper positioning of preterm infants may promote normal motor development while minimizing the development of abnormal movement patterns [4].

Preterm infants emerge from a safe uterine environment to a noisy, stressful and painful environment which intended to ensure the survival of preterm infants may instead alter their brain development and contribute to several learning and behavioral difficulties observed in later childhood[5]. Admission to the neonatal intensive care unit is considered a critical event to the infant growth and development, they being exposed to a series of painful and stressful stimuli for which it is not prepared [6, 7].Researchers have noted that preterm infants exposed to repeated painful experiences may manifest more heightened responses to pain that result from lower pain thresholds, and thus, they manifest greater physiological responses following a painful procedure [8].

Developmental care is the intervention taken to support the behavioral organization of each individual infant, minimize the stress, protecting sleep rhythms, enhancing physiological stability and promoting growth and maturation. These interventions include handling and positioning which may modify gate control mechanisms, thereby altering pain transmission, reduction of a noxious environmental stimuli and cue based care[9].Although preterm infants have well developed pain perception mechanisms, but do not have those required for pain modulation as in term infants or an adult. Pain assessment is the cornerstone of effective management of pain and has been associated with the increased use of analgesia to decrease pain, suffering and improve the quality of life [10].

Developmental supportive positioning is an intervention that has been proven to improve postural and musculoskeletal outcomes. As well as improve sleep states and physiological outcomes. Positioning of preterm infants is basic neonatal nursing care and one of the important aspects of developmental care to keep the preterm infants comfortable using supine, prone and side lying position as measured by infant positioning assessment tool $[1,11]$. However, developmental positioning is not a standardized intervention and various methods of providing developmental positioning have been used, these methods include the use of commercially available products in each NICU such as snuggle-up, as well as the use of simple linen rolls to provide boundaries and supports or" nesting " materials for preterm infant [12].

Handling and positioning of the preterm infant are the major interventions in NICU. When preterm infant was handled for reasons such as hygiene, diaper change, feeding, or for diagnostic or therapeutic procedures, can react negatively for several minutes until he/she becomes exhausted. This results in an unnecessary expenditure of energy that turn into physiological or behavioral instability and signs of distress and pain. Properly positioning by using of rolled-up towels or sheets have been proposed to form a 'nest' in order to provide postural, behavioral and physiological stability to the preterm infant ${ }^{[13]}$.Pediatric Nurses are central in hospital efforts to improve quality of care provided. Comforting interventions in the field of nursing care will contribute to high patient satisfaction and eventually will lead to institutional development [14].

\subsection{Significance of the Study}

Developmental positioning is an intervention that has been proven to improve postural, physiologic and musculoskeletal outcomes as well as improve sleep states of preterm infants $[15,16]$. Although the IPAT is an available valid and reliable tool, there have been limited published researches that used it, and little is known about how to improve the developmental positioning proficiency of the nurses providing the care at NICU [12]. Providing postural support during care provided could reduce the signs of distress and pain [10]. Hopefully, the present study would implement a developmentally supportive positioning approach that could decrease the preterm infants' pain response in NICU.

\subsection{Aim of This Study}

Investigate the effectiveness of developmentally supportive positioning on preterm infants' pain responses at NICU.

\subsection{Research Hypotheses}

I: Preterm infants who were placed in developmentally supportive positioning would had acceptable position

II: Preterm infants who had acceptable position after developmentally supportive positioning would exhibit less pain scores.

\section{Methodology}

\subsection{Design and Setting}

A quasi- experimental pre and post intervention was carried out on ten incubators in the level (I) of NICU at Mansoura University Children's Hospital. That provided ordinary care for stable cases such as simple preterm, low birth weight for weight gain only and hyperbilirubenmia who are need phototherapy and respiratory distress syndrome (RDS) grade I that don't need mechanical ventilation or CPAP as well as cases who are prepared for discharge.

\subsection{Sampling}

A convenient sample of all preterm infants (56) who were admitted to the previously mentioned setting during nine months. The sample were divided randomly into two identical groups, the study group (28) who receive the intervention and the control group (28) who receive only the routine care according to the unit policy after fulfilling the criteria of selection; Gestational age 28-34 weeks of gestation, low birth weight infant $\leq 2500$ gm, both genders. While Preterm infants who have malformations, neurological 
defect, on mechanical ventilation and who have received any sedatives or analgesics were excluded.

\subsection{Instrumentation}

Tool (1): Characteristics of Preterm Infants: It include data that extracted from infant's medical file and nurses' notes such as sex, gestational age, postnatal age, birth weight and diagnosis.

Tool (2): Infant Position Assessment Tool (IPAT). This tool was developed by Coughlin et al., (2010) ${ }^{[15]}$ as a teaching tool to standardize developmental supportive positioning practices in the NICU. It is a six- items tool with cumulative scores ranging from 0 to 12 . It consists of (Shoulder status, Hand and arm location, Pelvic Position, Knees, ankles/feet orientation, Head position, Chin/Neck position). It provides a method for evaluating positioning practice.

Scoring system: A score of 2 for appropriate (correct) positioning, a score 1 for acceptable alternative (inappropriate) positioning, and a score 0 for unacceptable (abnormal) positioning. A total score of 12 was given to perfect position according, score of $9<12$ was acceptable, score of 8 or lower indicate unacceptable position and infant is need for repositioning using developmentally supportive positioning.

Tool (3): Preterm Infant Pain Profile (PIPP): This tool was adopted from Stevens et al., (1996); Belleini et al., $(2007)^{[16,17]}$ It was used to measure the pain responses of preterm infants. It is a seven indicators pain measure that includes three behavioral responses (brow bulge, eye squeeze, and nasolabial furrow), two physiologic responses (heart rate and oxygen saturation), and two contextual responses (gestational age and behavioral state).

Scoring system: Each indicator is scored on a 4-point scale ( 0 to 3 ) to give a maximum total score of 21 , score zero indicate no pain and score 3 indicate severe pain. Total score 0 - 6 indicates the infant has minimal or no pain(no Action needed to preterm infant), while score 7-12 indicates slight to moderate pain and score $>12$ may indicate severe pain(need for developmental positioning).

\subsection{Data Collection Procedure}

Ethical considerations: Approval consent was obtained from the Research Ethics Committee at Faculty of Nursing, Mansoura University. Also an official permission obtained from the director of NICU and the head of the NICU after an explaining the aim, tools, duration and the benefits of the study. As well as oral consent was obtained from the parents of preterm infants after explaining the aim, the benefits and the time/duration of the study and their rights to accept or refuse their infant's participation without interference with the care provided.

Validity and reliability of tools: Tool 2 and Tool 3 were standardized; thus their validity were based on research evidence and opinions from clinical experts and their reliability were tested giving Cronbach's $\alpha$ of 0.972 for the second and 0.95 for the third tool.
Pilot study: A pilot study was done on $10 \%$ of the study sample ( 5 preterm infants) in order to assess the clarity, feasibility and applicability of the tool. Minor modifications were done consequently, the pilot study sample were excluded from the study.

Data were collected over a period of nine months from the beginning of October 2015 to the end of June2016.

\subsection{Intervention: Done Through Three Phases}

a Assessment phase: An initial assessment was carried out by the researcher for the study and control group before giving routine nursing care in morning shift the day before the intervention to collect baseline data about preterm infants' positions using tool (2) (pre and post intervention after one week) to assess and categorize preterm infant position. Then the researcher assess preterm infants pain response using tool (3) (pre- immediately post intervention throughout one week)while the infant is calm, 5 minutes before non invasive nursing procedures such as(bed bath, diaper change, eye care, cord care) the immediately after and 5 minutes later. The PIPP score was calculated and then categorize the preterm infants 'pain.

b Implementation phase: At the next day to assessment phase, the researcher was assigned each preterm infant in the study group inside the incubator in developmental supportive position (nest) during morning routine nursing care (non invasive procedures) by using materials such as linen, the researcher created it in multiple format such as Snuggle-Up (is like the uterus) and Bendy Bumper(is like the abdominal wall muscle), support was made of flexible and adjustable rolled linen to ensure body support, when the infants in different lying positions, such as in supine to reduce shoulder and hip abduction, maintain knee flexed and elevated, prevent head flattening, maintain a midline head position and hold shoulders forward to encourage hand to mouth movements. It was also designed to allow for spontaneous movement by the infant. Preterm infants received positional support as regular care throughout the day, for a full 24 hours for one week in different lying positions (prone or supine or lateral).

The researcher was educated the staff nurses working in NICU about of developmentally supportive positioning practices, through demonstration and re demonstration of nesting in order to be certain that they understood and maintain the preterm infants position (nest) during their routine care. Every infant was observed placed in the incubator in developmentally supportive positioning for 7 days to measure the pain responses of preterm infants before and after morning routine nursing care. However Preterm infants in control group were subjected only to routine unit care without interference from the researcher.

c Evaluation Phase:

- Evaluation of the studied preterm infants through collection of IPAT scores in both groups by 
researcher pre and post after one week.

- Pain evaluation was done by researcher for preterm infants in both groups for 7 days, every day from the 1 st day at the beginning of intervention to $7^{\text {th }}$ day, the researcher was designed an observation sheet to record the effects of the developmental positioning on the pain response (physiological and behavioral stability) of the preterm infants by using the (PIPP), it was done by researcher three times, 5 minutes before morning routine care, immediately after and 5 minutes later.

- Evaluate the relationship between developmentally supportive positioning and preterm infant's pain responses in the study group at one week post intervention.

\subsection{Limitation of the Study}

- Small sample size due to some of preterm infants was transferred to another NICU and others were died.

- The researcher was overburden with educating all nurses in INCU about implementing developmentally supportive positioning because the same nurses are not present over the whole time period.

\subsection{Statistical Analysis}

Statistical analyses were performed using SPSS for windows version 20.0 (SPSS, Chicago, IL). Continuous data were expressed as mean \pm standard deviation (SD), while categorical data were expressed in number and percentage. The differences between two groups were determined using independent samples Student's t test for variables with continuous data or chi-square test for variables containing categorical data. Statistical significance was set at $\mathrm{p}<0.05$.

\section{Results}

It was observed from (table 1) that more than half of the studied subjects were male $(64.3 \%)$ in the study group and $957.1 \%$ ) in the control group. Most cases admitted to NICU diagnosed with RDS I (35.7\%) in study and (39.3\%) in the control group followed by hyperbilirubenmia (25\%) \& (28.6) respectively then RDS II and simple preterm with a mean gestational age of $30.7 \pm 1.9$ weeks in the study group and $30.1 \pm 1.5$ weeks in control group respectively. The mean post-natal age of the preterm infants was $15.4 \pm 9.9$ days in study and $14.7 \pm 8.5$ days in control group. With average birth weight of $1822.2 \pm 148.7$ gm in study group and $1867.1 \pm$ $147.5 \mathrm{gm}$ in the control group. There is no statistical difference between the two groups ( $p>0.05)$.

The baseline assessment of preterm infant's positioning and pain score in (table 2) clarified that all the preterm infants $(100 \%)$ had an unacceptable positioning in both group. And none of preterm infants in both groups had no-orminimal pain, about three quarter in both group $(71.4 \% \%$ $75 \%$ ) have slight to moderate pain and only about one quarter in both group $(28.6 \% \& 25 \%)$ have severe pain 5 minutes before morning routine care. While immediate after routine care $25 \%$ in the study and $28.6 \%$ in the control had slight to moderate pain respectively and $75 \%$ \& $71.4 \%$ respectively had severe pain. After 5 minutes post routine care $46.4 \%$ \& $42.9 \%$ had slight to moderate pain in the study and control group and more than half of preterm infants $(53.6 \%$ \& $57.1 \%$ ) respectively had severe pain in both group. With no significant difference $(p=>0.05)$.

Figure1: Clarifies preterm infant positioning at one-week evaluation of using developmentally supportive intervention. It is clear that about two third $(64.3 \%)$ of the infants were placed in an acceptable position in the study group, while only less than one quarter $(21.4 \%)$ of the preterm infants in the control group were placed in an acceptable position,. This difference was highly statistically significant $(\mathrm{p}=<0.001)$.

It was observed from Table 3 that the PIPP score did not differ significantly between both groups at the $1^{\text {st }}$ and $2^{\text {nd }}$ day of using developmentally supportive positioning. The pain score start to decrease from the $3^{\text {rd }}$ day of intervention till $6^{\text {th }}$ day with a highly statistical significance difference in both group $(\mathrm{p}<0.001)$.

Figure 2: represent preterm infant's pain response at one week of implementing developmentally supportive positioning in both groups. It is clear that at the $7^{\text {th }}$ day of intervention, five minutes before morning routine care, about three quarters $(78.6 \%)$ of infants in the study group had noor-minimal pain while none of infants in the control group had no-or-minimal pain and about one third $(32.1 \%)$ of infants in the control group had severe pain and none of the infants in the study group had severe pain $(p<0.001)$. Immediately after procedure, $25 \%$ of infants in the study group had no-or-minimal pain while none of infants in the control group had no-or-minimal pain and $53.6 \%$ of infants in the control group had severe pain whereas only $7.1 \%$ of the infants in the intervention group had severe pain $(p<0.001)$. Five minutes after procedure, about half $(53.6 \%)$ of infants in the study group had no-or-minimal pain while none of infants in the control group had no-or-minimal pain and about one third (32.1\%) of infants in the control group had severe pain and none of the infants in the study group had severe pain. This difference was highly statistical significance $(\mathrm{p}<0.001)$.

Table 4: demonstrates the relationship between the Premature Infant Pain response and their position in the study group at one-week post intervention. The preterm infants who had severe pain $(20 \%)$ immediately after routine care were from those placed in an Unacceptable positioning while none of the preterm infants who were placed in an acceptable positioning had severe pain. On the other hand, $(94.4 \%$ and $77.8 \%$ respectively) of the preterm infants with no-orminimal pain care were placed in an acceptable positioning at 5 minutes before morning routine care and post 5 minutes compared to (50\% and $10 \%$ respectively) of infants placed in an unacceptable positioning. These relation were highly significant $(p=<0.001)$. 
Table 1. Characteristics of the preterm infants in the study and control groups.

\begin{tabular}{|c|c|c|c|c|c|c|}
\hline \multirow{2}{*}{ Items } & \multicolumn{2}{|c|}{ Study group(n=28) } & \multicolumn{2}{|c|}{ Control group $(n=28)$} & \multicolumn{2}{|c|}{ Student's t test } \\
\hline & NO & $\%$ & NO & $\%$ & $\mathbf{t}$ & $\mathbf{P}$ \\
\hline Gender: Male & 18 & 64.3 & 16 & 57.1 & & \\
\hline Female & 10 & 35.7 & 12 & 42.9 & 0.299 & 0.585 \\
\hline \multicolumn{7}{|l|}{ Diagnosis } \\
\hline - Simple preterm & 5 & 17.9 & 4 & 14.3 & \multirow{4}{*}{0.316} & \multirow{4}{*}{0.957} \\
\hline - RDS I & 10 & 35.7 & 11 & 39.3 & & \\
\hline - RDS II & 6 & 21.4 & 5 & 17.9 & & \\
\hline - Hyperbilirubenmia & 7 & 25 & 8 & 28.6 & & \\
\hline Gestational age (weeks)Mean \pm SD & \multicolumn{2}{|c|}{$30.7 \pm 1.9$} & \multicolumn{2}{|c|}{$30.1 \pm 1.5$} & 1.312 & 0.346 \\
\hline Postnatal age (days)Mean \pm SD & \multicolumn{2}{|c|}{$15.4 \pm 9.9$} & \multicolumn{2}{|c|}{$14.7 \pm 8.5$} & 0.284 & 0.834 \\
\hline \multicolumn{7}{|l|}{ Birth weight (gm) } \\
\hline Range & \multicolumn{2}{|c|}{$(1600-2150)$} & \multicolumn{2}{|c|}{$(1650-2200)$} & 1.135 & 0.261 \\
\hline Mean \pm SD & \multicolumn{2}{|c|}{$1822.2 \pm 148.7$} & \multicolumn{2}{|c|}{$1867.1 \pm 147.5$} & & \\
\hline
\end{tabular}

Table 2. The baseline assessment of preterm infant position and Pain Profile scores in the study and control group using routine nursing care (Pre intervention).

\begin{tabular}{|c|c|c|c|c|c|c|}
\hline \multirow{2}{*}{ Items } & \multicolumn{2}{|c|}{ Study group $(n=28)$} & \multicolumn{2}{|c|}{ Control group $(n=28)$} & \multicolumn{2}{|c|}{ Chi square test } \\
\hline & $\mathbf{N}$ & $\%$ & $\mathbf{N}$ & $\%$ & $\mathbf{X 2}$ & $\mathbf{P}$ \\
\hline \multicolumn{5}{|c|}{ Studied Preterm infant 's positioning at baseline (pre intervention) } & \multirow{5}{*}{0.000} & \multirow{5}{*}{1.000} \\
\hline Unacceptable positioning & 28 & $100 \%$ & 28 & $100 \%$ & & \\
\hline Acceptable positioning & 0 & $0 \%$ & 0 & $0 \%$ & & \\
\hline Perfect positioning & 0 & $0 \%$ & $0 \%$ & $0 \%$ & & \\
\hline \multicolumn{5}{|c|}{ Studied preterm infant's pain profile at baseline (Pre intervention) } & & \\
\hline \multicolumn{5}{|c|}{ Pre( 5 minutes) before routine care } & \multirow{5}{*}{0.091} & \multirow{5}{*}{0.763} \\
\hline No-or-minimal & 0 & 0 & 0 & 0 & & \\
\hline Slight-to-Moderate & 20 & 71.4 & 21 & 75 & & \\
\hline Severe & 8 & 28.6 & 7 & 25 & & \\
\hline \multicolumn{5}{|l|}{ Immediate after routine care } & & \\
\hline No-or-minimal & 0 & 0 & 0 & 0 & \multirow{4}{*}{0.091} & \multirow{3}{*}{0.763} \\
\hline Slight-to-Moderate & 7 & 25 & 8 & 28.6 & & \\
\hline Severe & 21 & 75 & 20 & 71.4 & & \\
\hline \multicolumn{5}{|c|}{ Post (5 minutes) after routine care } & & \\
\hline No-or-minimal & 0 & 0 & 0 & 0 & \multirow{3}{*}{0.072} & \multirow{3}{*}{0.788} \\
\hline Slight-to-Moderate & 13 & 46.4 & 12 & 42.9 & & \\
\hline Severe & 15 & 53.6 & 16 & 57.1 & & \\
\hline
\end{tabular}

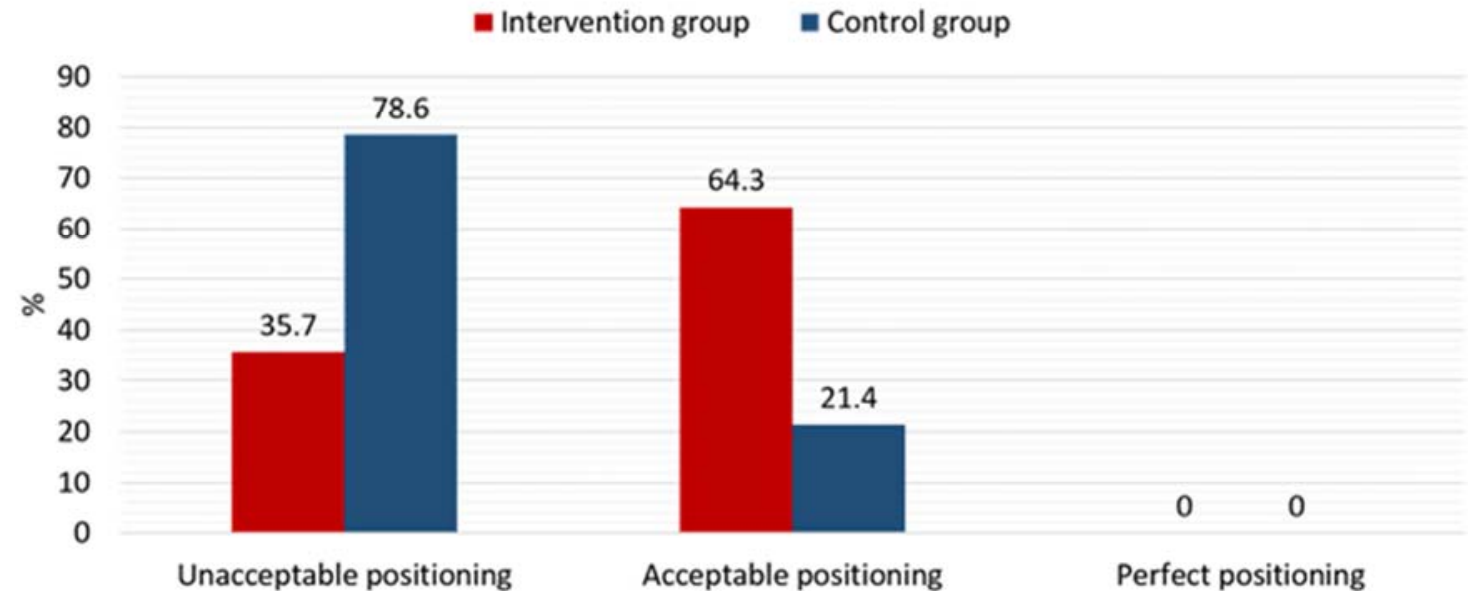

Figure 1. Studied preterm infant's positioning assessment after one week of using developmentally supportive positioning in the study and control group (Post intervention). 
Table 3. Preterm Infant Pain Profile in the study and control groups through one week of using developmentally supportive positioning.

\begin{tabular}{|c|c|c|c|c|c|c|c|c|c|c|c|c|c|c|}
\hline & \multicolumn{6}{|c|}{ Study group $(n=28)$} & \multicolumn{6}{|c|}{ Control group $(n=28)$} & \multirow{2}{*}{\multicolumn{2}{|c|}{ Chi square Test }} \\
\hline & \multicolumn{2}{|c|}{ No-or-minimal } & \multicolumn{2}{|c|}{ Slight-to-Moderate } & \multicolumn{2}{|c|}{ Severe } & \multicolumn{2}{|c|}{ No-or-minimal } & \multicolumn{2}{|c|}{ Slight-to-Moderate } & \multicolumn{2}{|c|}{ Severe } & & \\
\hline & $\mathbf{N}$ & $\%$ & $\mathbf{N}$ & $\%$ & $\mathbf{N}$ & $\%$ & n & $\%$ & $\mathbf{N}$ & $\%$ & $\mathbf{N}$ & $\%$ & $\mathrm{X} 2$ & $\mathbf{P}$ \\
\hline \multicolumn{15}{|l|}{$1^{\text {st }}$ day } \\
\hline pre(5minutes) & 1 & 3.6 & 19 & 67.9 & 8 & 28.6 & 0 & 0 & 21 & 75 & 7 & 25 & 1.167 & 0.558 \\
\hline Immediate & 0 & 0 & 12 & 42.6 & 16 & 27.1 & 0 & 0 & 8 & 28.6 & 20 & 71.4 & 1.244 & 0.537 \\
\hline Post(5minutes) & 1 & 3.6 & 17 & 60.7 & 10 & 35.7 & 0 & 0 & 15 & 53.6 & 13 & 46.4 & 1.516 & 0.469 \\
\hline \multicolumn{15}{|l|}{$2^{\text {nd }}$ day } \\
\hline Immediate & 2 & 7.1 & 16 & 57.1 & 10 & 35.7 & 0 & 0 & 13 & 46.4 & 15 & 53.6 & 3.310 & 0.191 \\
\hline Post(5minutes) & 3 & 10.7 & 17 & 60.7 & 8 & 28.6 & 0 & 0 & 18 & 64.3 & 10 & 35.7 & 3.251 & 0.197 \\
\hline \multicolumn{15}{|l|}{$3^{\text {rd }}$ day } \\
\hline $\operatorname{pre}(5$ minutes $)$ & 7 & 25 & 17 & 60.7 & 4 & 14.3 & 0 & 0 & 18 & 64.3 & 10 & 35.7 & 9.600 & 0.008 \\
\hline Immediate & 0 & 0 & 17 & 60.7 & 11 & 39.3 & 0 & 0 & 12 & 42.6 & 16 & 27.1 & 1.788 & 0.409 \\
\hline Post(5minutes) & 3 & 10.7 & 19 & 37.9 & 6 & 21.4 & 0 & 0 & 20 & 71.4 & 8 & 28.6 & 3.311 & 0.191 \\
\hline \multicolumn{15}{|l|}{$4^{\text {th }}$ day } \\
\hline Immediate & 2 & 7.1 & 18 & 64.3 & 8 & 28.6 & 0 & 0 & 10 & 35.7 & 18 & 64.3 & 8.132 & 0.017 \\
\hline Post(5minutes) & 4 & 14.3 & 19 & 67.9 & 5 & 17.9 & 0 & 0 & 20 & 71.4 & 8 & 28.6 & 4.718 & 0.095 \\
\hline \multicolumn{15}{|l|}{$5^{\text {th }}$ day } \\
\hline pre(5minutes) & 14 & 50 & 14 & 50 & 0 & 0 & 0 & 0 & 21 & 75 & 7 & 25 & 22.400 & $<0.001$ \\
\hline Immediate & 4 & 14.3 & 20 & 71.4 & 4 & 14.3 & 0 & 0 & 10 & 35.7 & 18 & 64.3 & 16.242 & $<0.001$ \\
\hline \multicolumn{15}{|l|}{$6^{\text {th }}$ day } \\
\hline pre(5minutes) & 18 & 64.3 & 10 & 35.7 & 0 & 0 & 0 & 0 & 22 & 78.6 & 6 & 21.4 & 25.625 & $<0.001$ \\
\hline Immediate & 6 & 21.4 & 19 & 67.9 & 3 & 10.7 & 0 & 0 & 12 & 42.6 & 16 & 27.1 & 16.475 & $<0.001$ \\
\hline Post(5minutes) & 9 & 32.1 & 19 & 67.9 & 0 & 0 & 0 & 0 & 22 & 78.6 & 6 & 21.4 & 15.220 & $<0.001$ \\
\hline
\end{tabular}

$(* *)$ highly statistical significance at $\mathrm{p}<0.001$.

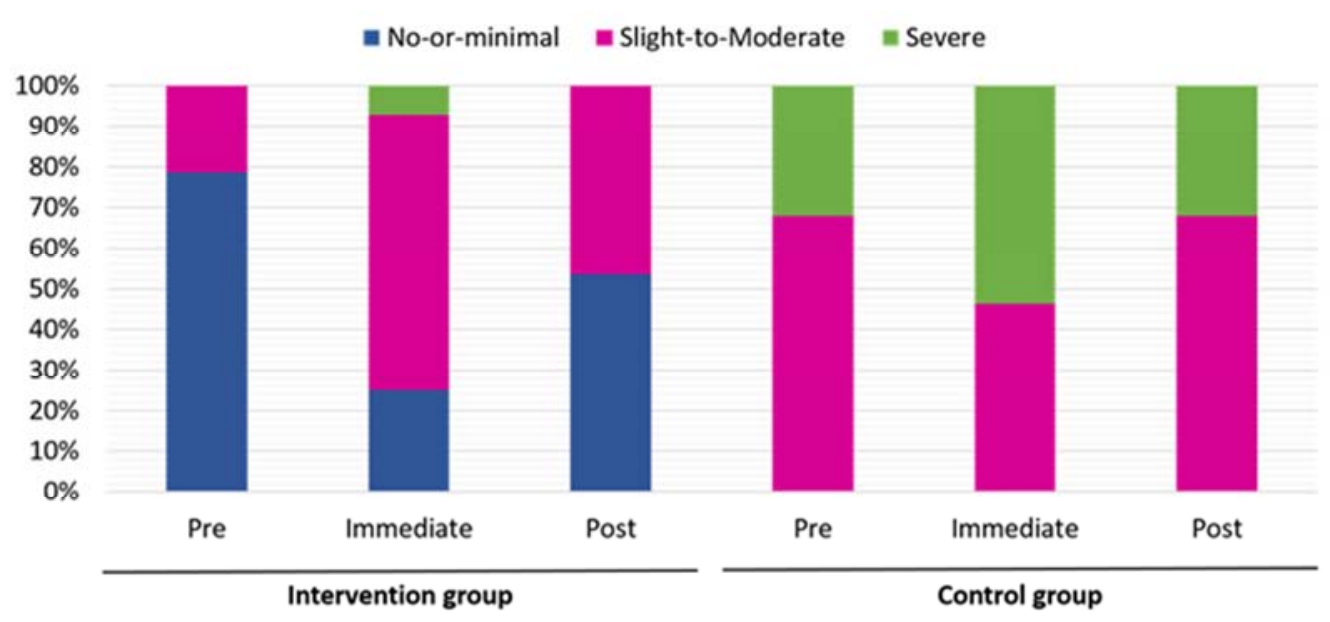

Figure 2. The comparison of Preterm Infant Pain Profile between the study and control group at $7^{\text {th }}$ day post intervention.

Table 4. The relationship between studied preterm positioning and pain responses at one-week post intervention in study group ( $n=28)$.

\begin{tabular}{|c|c|c|c|c|c|c|}
\hline & \multicolumn{2}{|c|}{ Unacceptable positioning $(n=10)$} & \multicolumn{2}{|c|}{ Acceptable positioning $(n=18)$} & \multicolumn{2}{|c|}{ Chi square test } \\
\hline & $\mathbf{N}$ & $\%$ & $\mathbf{N}$ & $\%$ & $\mathbf{X 2}$ & $\mathbf{P}$ \\
\hline \multicolumn{7}{|l|}{ pre( 5 minutes) before routine care } \\
\hline No-or-minimal & 5 & 50 & 17 & 94.4 & \multirow{3}{*}{7.542} & \multirow{3}{*}{0.006} \\
\hline Slight-to-Moderate & 5 & 50 & 1 & 5.6 & & \\
\hline Severe & 0 & 0 & 0 & 0 & & \\
\hline \multicolumn{7}{|l|}{ Immediate after routine care } \\
\hline No-or-minimal & 0 & 0 & 7 & 38.9 & \multirow{3}{*}{7.827} & \multirow{3}{*}{0.020} \\
\hline Slight-to-Moderate & 8 & 80 & 11 & 61.1 & & \\
\hline $\begin{array}{l}\text { Severe } \\
\operatorname{post}(5 \text { minutes }) \text { after routine care }\end{array}$ & 2 & 20 & 0 & 0 & & \\
\hline No-or-minimal & 1 & 10 & 14 & 77.8 & \multirow{3}{*}{11.873} & \multirow{3}{*}{$<0.001$} \\
\hline Slight-to-Moderate & 9 & 90 & 4 & 22.2 & & \\
\hline Severe & 0 & 0 & 0 & 0 & & \\
\hline
\end{tabular}




\section{Discussion}

Preterm infants exhibit physiological and behavioral signs of pain and stress that can be recognized by professional health staff, pharmacological and non-pharmacological modalities may be used to manage such conditions. Appropriate developmentally supportive positioning is considered an important non-pharmacological intervention that could decrease pain responses in high risk patients admitted to NICU [19].

Concerning characteristics of studied preterm infants (Table 1) the current results indicated that more than half of them in both groups were males. This result was in agreement with the Egypt Demographics Profile (2012) [20] who stated that the prematurity sex ratio at birth was 1:05 male/female. Also the mean gestational age of the preterm infants were $30.7 \pm 1.9$ weeks in study group and $30.1 \pm 1.5$ weeks in control, with mean birth weight of $1822.2 \pm 148.7$ gms and $1867.1 \pm 147.5$ gms for both groups respectively. This result supported by Alberman, (2008) [21] who indicated that, premature deliveries were associated with higher rates of low birth weight compared to full term deliveries, whereas the risk is increased 13 times with premature delivery. According to Picheansathian et al., (2009) [22] preterm infants usually unable to perform any of body functions without multiple medical interventions and specialized nursing care, which aimed at reducing energy expenditure and conserving effort to maximize growth and development. Concerning the diagnosis of studied preterm infants, the present study results highlighted that, more than one third of studied infants admitted to NICU diagnosed with RDS I in both groups followed by about one quarter with hyperbilirubenmia then RDS II and simple preterm. This result was in disagreement with Mohammed, Hassan and Mohmoud,(2014) [23]. who found that, Neonatal jaundice is generally considered a benign self-limiting condition, affecting about two third of healthy full term and late preterm newborn infants.

Regarding baseline assessment of preterm infant's positioning and pain score (table 2), the present study revealed that, all the preterm infants had an unacceptable positioning in both groups. And none of preterm infants in both groups had no- or- minimal pain before intervention. This may because absence of standardized policy of care regarding using of appropriate positioning for alimenting stressful events aggravating pain at NICU. These findings are consistent with the result of Ramya, Molly and Sharda, $(2015){ }^{[24]}$ who found no significant difference in the mean pre-test posture scores and discomfort scores of low birth weight preterm infants in the experimental and control groups before administration of nesting.

However post implementation of developmentally supportive positioning (Figure 1), the present study revealed that, about three quarters of the preterm infants had acceptable position in study group compared to Less than one quarter had acceptable position in control group after one week of intervention. This attributes the researcher effects in implementing preterm body parts in comfortable alignment. This result was in agreement with the result of Chen et al., (2014) and Jeanson, (2013) [16, 25] that found in their study that, the mean IPAT scores improved after introducing the IPAT tool and making educational materials available in NICU and apply it on preterm infants was increased their developmental positioning scores. As well as, Ramya, Molly and Sharda, 2015) [24] who showed that mean post-test posture score of low birth weight infants in the experimental group was significantly higher than the mean pre-test posture scores.

Concerning preterm infants pain profile score throughout one week (Table 3 ), the present study revealed that, the pain score did not differ significantly between both groups at the $1^{\text {st }}$ and $2^{\text {nd }}$ day of using developmentally supportive positioning. The pain score start to decrease from the $3^{\text {rd }}$ day of intervention till $6^{\text {th }}$ day with a highly statistical significance difference in both groups. This may attribute to when preterm infants were placed in the developmentally supportive positioning and maintain their normal body flexions this promote preterm infant comfort and sustain their physiological and behavioral responses normally that consequently decrease the pain sensation.

While at the $7^{\text {th }}$ day after intervention (Figure 2)five minutes before morning routine care, about three quarters of infants in the study group had no-or-minimal pain compared to non in the control group. While, about one third of infants in the control group had severe pain and none in the study group had severe pain. As well as five minutes after procedure, about half of infants in the study group had no-orminimal pain while none of infants in the control group had no-or-minimal pain and about one third of infants in the control group had severe pain and none of the infants in the study group had severe pain. This reflect the efficacy of researcher teaching to nursing staff at NICU about the importance of adopting developmentally positioning during their nursing intervention using available materials as rolled linen which also eliminate control group pain score. This finding was in agreement with the result of Holsti, Grunau, Oberlander, and Whitfiels (2014) [26] who found in their study that, the distress and pain scores associated with diaper change was significantly less during the nested condition compared with the non-nested.

Findings of the present study showed that a significant positive relationship between the Premature Infant Pain response and their position in the study group at one-week post intervention (Table 4), this may because when infant position assessment score increase this indicate appropriate accepted position and when the pain profile score decreased this indicate no-or-minimal pain that results from appropriate position stability. These findings are consistent with the result of Jeanson. (2013) [16] who demonstrated that, a favorable effect of the nesting intervention and decrease pain score observed in the nested condition, self-regulation when nested, due to postural stability, reduction of energy 
expenditure and easy movement of their limbs to the midline.

Finally, by evaluating the effect of implementation of the developmentally supportive positioning on preterm infants' pain in NICU, an improvement was observed among the preterm infant position and response to pain. So, developmentally supportive positioning contributed to decrease preterm infants' pain.

\section{Conclusion}

The present study concluded that preterm infants who were placed in developmentally supportive positioning had acceptable position and exhibited less pain scores. These results support the proposed study hypotheses.

\section{Recommendations}

Based on the findings of the present study it is recommended that:

- Replication of the present study on a larger sample.

- Painful procedures should be done while preterm infant in developmental supportive positioning.

- Educational programs are recommended to improve NICU nurses' knowledge and practice about developmental supportive positioning.

- Future researches could focus on the effect of the IPAT on the infants' long term outcomes such as musculoskeletal development, or the need for physical therapy.

\section{References}

[1] Symington, A. J., \&Pinelli, J. (2006). Developmentalcare for promoting development and preventing morbidity in preterm infants. Cochrane Database of Systematic Reviews, http://dx.doi.org/10.1002/14651858.CD001814.pub2.

[2] Blencowe, H., Cousens, S., Chou, M and Mollar, A. (2012). National, Regional and Worldwide estimates of pretermbirth. The Lancet, 379(9832), 2162-2172.

[3] Federal Interagency Forum on Child and Family Statistics. (2013). America's children: Key national indicators of wellbeing. Washington, DC: Government Printing Office.

[4] Rick, S. L. (2006). Developmental care on newborn intensive care units nurse's experiences and neuro-developmental behavioral and parenting outcomes. A critical review of the literature. Journal of Neonatal Nursing, 12(2):56-61.

[5] Louw, R., and Maree, C. (2005). The effect of formal exposure to developmental care principles on the implementation of developmental care positioning and handling of preterm infants by neonatal nurses. Health $S A$ Gesondheid, 10(2): 24-32.

[6] Solhaug, M., Bjork, I. and Sandtro, H. (2010): Staff perception of one year after implementation of the newborn individualized developmental care and assessment Program (NIDCAP). Journal of Pediatric Nursing, 25 (2), 89-97.

[7] Jane, A., Chrissie Israel. (2008). Developmental Care - mapping the way forward in the Uk: a BLISS initiative, Journal of Neonatal Nursing. www.neonatalNsg.co.Uk/Pdf/inf, 4(3):80-83.

[8] Chimello, gaspardo, Cugler, Martinez and Linhares. (2009).Pain reactivity and recovery in preterm neonates: latency, magnitude, and duration of behavioral responses. Early Human Development; 85(5): 313-8. doi: 10.1016/j.earlhumdev.

[9] Linda, M. C. (2011). Assessment of preterm infants readiness to commence breastfeeding, Queenslan University of Technology; (unpublished).

[10] Comaru, T., and Miura, E. (2009). Postural support improves distress and pain during diaper change in preterm infants, Journal of Perinatology, 8(2): 504-507.

[11] Hendricks-Munoz, K. D., Prendergast, C. C., Caprio M, C and Wasserman R. S. (2002). Developmental care: The impact of Wee Care developmental care training onshort-term infant outcome and hospital costs. Newborn Infant Nurs Rev, 2(1): $39-45$.

[12] Madlinger-Lewis, L., Reynolds, L., Zarem, C., Crapnell, T., Inder, T., and Pineda, R. (2014). The effects of alternative positioning on preterm infants in the neonatal intensive care unit: A randomized control trial. Research in Developmental Disabilities, 35, 490-497. http://dx.doi.org/10.1016jj.ridd.2013.11.019.

[13] Stevens, B., and Gibbins, S. (2002). Clinical utility and clinical significance in the assessment and management of pain in vulnerable infants. Clin Perinatol, 29(3): 459-468.

[14] Coughlin, M., Gibbins, S., \& Hoath, S. (2009). Core measures for developmentally supportive care in neonatal intensive care units: Theory, precedence and practice. Journal of Advanced Nursing, 65(10), 2239-2248. http://dx.doi.org/10.1111/j.13652648.2009.05052. X.

[15] Coughlin, M., Lohman, M. B., and Gibbins, S. (2010). Reliability and effectiveness of an infant positioning assessment tool to standardize developmentally supportive positioning practices in the neonatal intensive care unit. Newborn and Infant Nursing Reviews, 10(2), 104-106. http://dx.doi.org/http: //dx.doi.org/10.1053/j.nainr.2010.03.003.

[16] Jeanson, E. (2013). One-to one bedside nurse education as a means to improve positioning consistency. Newborn and Infant Nursing Reviews, 13(1): 27-30" http://dx.doi.org.1053/j.nainr

[17] Stevens, B. J., Johnston, C., Petryshen, P., and Taddio, A. (1996). Premature Infant Pain Profile: Development and initial validation. The Clinical Journal of Pain, 12(1), 13-22.

[18] Bellieni, C.V., Cordelli, D.M., Caliani, C., Palazzi, C., Franci, N., Perrone, S., andBuonocore, G. (2007). Inter-observer reliability of two pain scales for newborns. Early Human Development, 83(8): 549-552.

[19] Coughlin M, Gibbins S, Hoath S. (2014) Core measures for developmentally supportive care in neonatal intensive care units: theory, precedence and practice. Journal of Advanced Nursing. 65(10), 2239-2248.

[20] Egypt Demographic Profile (2012): Available at www.indexmundi.com/ Egypt. Accessed at 20/8/2013. 
[21] Alberman, E. (2008): Low Birth Weight and Prematurity, A Report from the National Institute of Child Health and Human Development, Neonatal Research Network. The Journal of Pediatric 130: 72-76.

[22] Picheansathian, W., Woragidpoonpol, P., and Baosoung, C. (2009). Positioning of preterm infants for optimal physiologic development: A systematic review. Joanna Brigss Institute Library of Systematic Reviews, 7(7): 224-259.

[23] Mohammed, S., Hassan, M., and Mahmoud, F. (2014). The Effect of Developmentally Supportive Care Training Program on Nurses' Performance and Behavioral Responses of Newborn Infants. Journal of Education and Practice, 5(6): 134-144.
[24] Ramya, P., Molly, B., and Sharda, R. (2015). Effect of Nesting on Posture Discomfort and Physiological Parameters of Low Birth Weight Infants, Journal of Nursing and Health Science, 4(1): PP 46-50.

[25] Chen, C. M., Lin, K. H., Su, H. Y., Lin, M. H., and Hsu, C. L. (2014). Improving the positioning and nesting for premature infants by nurses in neonatal intensive care units [Supplement]. $\mathrm{Hu} \mathrm{Li}$ ZaZhi, 61. http://dx.doi.org/10.6224/JN.61.2.41.

[26] Holsti, L., Grunau, R. E., Oberlander, T. F., and Whitfiels, M.F. (2014). Specific newborn individualized developmental care and assessment program movements are associated with acute pain in preterm infants in the neonatal intensive care unit. Pediatrics, 114(1): 65-72. 